\title{
BMJ Open Parental migration patterns and risk of depression and anxiety disorder among rural children aged 10-18 years in China: a cross-sectional study
}

\author{
Min Shen, ${ }^{1}$ Jing Gao, ${ }^{1}$ Zenzen Liang, ${ }^{1}$ Youjie Wang,${ }^{1}$ Yukai Du, ${ }^{1}$ Lorann Stallones ${ }^{2}$
}

To cite: Shen M, Gao J, Liang Z, et al. Parental migration patterns and risk of depression and anxiety disorder among rural children aged 10-18 years in China: a cross-sectional study. BMJ Open 2015;5:e007802. doi:10.1136/bmjopen-2015007802

- Prepublication history for this paper is available online. To view these files please visit the journal online (http://dx.doi.org/10.1136/ bmjopen-2015-007802).

Received 28 January 2015 Revised 9 September 2015 Accepted 6 October 2015

\section{CrossMark}

${ }^{1}$ Department of Maternal and Child Health, School of Public Health, Tongji Medical College, Huazhong University of Science \& Technology, Wuhan, Hubei, China

2Department of Psychology, Colorado Injury Control Research Center, Colorado State University, Fort Collins, Colorado, USA

\section{Correspondence to}

Dr Min Shen; shenmin5033@ hotmail.com

\section{ABSTRACT}

Objectives: This study aims to explore the prevalence of depression and anxiety in left-behind children, and to identify patterns of parents' migration and relative factors associated with depression and anxiety risk in this population.

Setting: A cross-sectional survey using a schoolbased sample was conducted in Puyang, Hebei, North China in December 2012.

Participants: 2283 students aged 10-18 years.

Main outcome measures: Parental migration status, depression and anxiety disorder.

Results: $61.2 \%$ of participants were left-behind children. The prevalence rate of depression among leftbehind children with both parents migrating (14.2\%) was higher than that of children with one parent migrating $(11.7 \%)$ and no parent migrating $(12.6 \%)$. The prevalence rate of anxiety disorder for children with no parent migrating $(25.1 \%)$ was higher than that for children living with one or neither parent $(22.2 \%$ and $22.0 \%)$. The risk factors for depression were low-level social support ( $\mathrm{OR}=3.46,95 \% \mathrm{Cl} 2.00$ to 6.01 ), average academic performance (OR=2.37, $95 \% \mathrm{Cl} 1.7$ to 3.3 ) and low academic performance (OR=3.01, 95\% $\mathrm{Cl} 1.92$ to 4.72$)$, staying up late $(\mathrm{OR}=1.67,95 \% \mathrm{Cl} 1.17$ to 2.39), having difficulty falling asleep ( $O R=2.04,95 \% \mathrm{Cl}$ 1.48 to 2.82$)$ and being an only child $(\mathrm{OR}=1.73,95 \% \mathrm{Cl}$ 1.04 to 2.89 ). The factors associated with anxiety disorder were being female $(\mathrm{OR}=2.09,95 \% \mathrm{Cl} 1.64$ to 2.66), being in high school ( $O R=1.8,95 \% \mathrm{Cl} 1.38$ to 2.36), physical abuse (OR=1.5, 95\% $\mathrm{Cl} 1.04$ to 2.15 ), having difficulty falling asleep $(\mathrm{OR}=1.67,95 \% \mathrm{Cl} 1.33$ to 2.10$)$ and low-level social support $(\mathrm{OR}=2.17,95 \% \mathrm{Cl}$ 1.44 to 3.28 ) and middle-level social support $(\mathrm{OR}=1.82$, $95 \% \mathrm{Cl} 1.3$ to 2.56 ).

Conclusions: Parents' migration was not associated with depression and anxiety in rural children aged 1018 years, but academic performance at school, sleep problems and lack of social support were associated with depression and anxiety.

\section{INTRODUCTION}

The migration of rural people for jobs and better income to cities has resulted in the separation of many families, leaving their

\section{Strengths and limitations of this study}

- This study found that children with both parents migrating had higher rates of depression than children living with one or two parents. Children living with both parents had a higher rate of anxiety than left-behind children.

- Academic performance at school, sleep problems and lack of social support were associated with higher prevalence rates of depression and anxiety disorder in rural children.

- This study showed that there was no significant association between parents' migration and psychological symptoms of depression and anxiety in children aged 10-18 years in rural North China. The main reason may be that most leftbehind children lived with their mothers.

- The participants were a convenience sample from one rural county in North China, thereby limiting our ability to generalise the findings to left-behind children in other areas of the country.

- The sample was recruited from schools, which limited our ability to examine the impact of parental migration on school attendance.

- Owing to a small sample of mother-only-migration $(1.8 \%)$, we could not assess differences in depression and anxiety disorder between mother-only-migration and father-only-migration.

families behind until spring festival days every year. An enormous number of rural residents, estimated at 269 million, moved to cities according to the China Women's Federation; most were aged 25-49 years. They return home and are reunited with the families for less than 1 month, and then leave again. Most of those left behind are children who cannot move to the city with their parents due to financial constraints and the school registration system, which requires that they stay at their rural home to study. This situation leaves over 60 million children in rural areas in China without one or both of their parents. ${ }^{1}$ 
Left-behind children have drawn attention from researchers in psychology and sociology. ${ }^{2-4}$ Recent studies showed that children separated from parents were disadvantaged in developmental and social emotional health; for example, left-behind children had a higher prevalence of depression, anxiety, substance abuse and suicide than non-left-behind children. ${ }^{5}{ }^{6}$ The absence of parental care and supervision and low family support were related to mental disorders in previous studies. ${ }^{7}$ Senaratne et al also found that left-behind children with migrating mothers in Sri Lanka had a higher prevalence of mental health problems than non-left-behind children. A review found that leftbehind children were more likely to have conflicts with peers and teachers, have more anxiety, lower self-esteem, higher suicidal behaviour and higher substance abuse than children living with their parents. ${ }^{8}$

The common view is that parental migration adversely impacts left-behind children. ${ }^{9}$ However, some researchers have found that parental migration had a positive effect on early cognitive development, which offsets the potential negative early childhood development effects from temporary lack of parenting. ${ }^{10}$ Other researchers have shown that parental migration had positive and negative impacts on left-behind children. Migration may enhance the well-being of left-behind children as well as of their families. ${ }^{11}$ Childhood development is likely to depend on a combination of nutrition, stimulation, home inputs, health and parents' socioeconomic status. Given the traditional role of parents in providing nutrition and healthcare in rural China, the absence of parents might affect the quality of diet, food preparation and illness care. If these things could be done by one parent (mother) or by grandparents (in a Chinese traditional family structure, mother and grandmother are the main caregivers of children), the negative impact of single parent migration on children could be minimal.

The impact of parents' migration on children's developmental and mental health needs detailed research. We were interested in diverse forms of parental migration, including families with a single parent, those with both parents living away from their children and those with no parent migrating. The purpose of this study was to compare the prevalence rates of depression and anxiety disorder among left-behind children and non-left-behind children, to explore the risk factors for mental disorders using multivariate logistic regression, and to determine the effects of parental migration status and related factors on children's mental health.

\section{METHODS}

\section{Sample}

A cross-sectional design was used to conduct the study. Structured interviews were performed among students from two high schools in December 2012 in Nanle county, Puyang city, Henan province. There are a total of 10 junior high schools and 1 senior high school in the county. Two middle schools were randomly selected from the 10 rural junior high schools and 12 classes were randomly selected from 54 classes in the senior high school, representing grades 7 th-12th, yielding 2500 respondents. A total of 2315 returned questionnaires, of which 2283 were complete and these were included in data analysis.

\section{Measures}

Demographic information of participants included sex, age, grade, whether or not they were an only child, school performance, family-related factors (such as education and occupation of parents, family income, parents' migration status in the past 6 months, and number of siblings) and health status (eyesight, disability and chronic diseases, etc).

Left-behind children refer to rural registered children less than 18 years of age where one or both of their parents migrate to urban areas for work, and where the children are left at home for at least 6 months, those children whose parent(s) were deceased, divorced or unknown were not included in this study.

Depression: The Children's Depression Inventory (CDI, simple Chinese version) was used to measure depressive symptoms of students. ${ }^{12}$ The CDI is a 27 -item scale that is self-rated and symptom oriented. We used a simplified Chinese version of CDI due to the high validity and reliability (Cronbach's $\alpha=0.85-0.88) .{ }^{13}{ }^{14}$ Individuals can score 0 54 with each statement being identified with a rating from 0 to 2 . The higher score indicates more severe depressive symptoms. Scoring 20 and higher indicated depression.

Anxiety disorder. The Screen for Child Anxiety Related Emotional Disorders (SCARED) was used to assess anxiety symptoms of children in this study. SCARED was established in 1997 by Birmaher et al ${ }^{15}$ to measure anxiety among children aged $9-18$ years. SCARED is a reliable and valid anxiety screening instrument in Chinese children aged 6-16 years, with high internal consistency $(\alpha=0.43-0.89)$ and test-retest reliability (intraclass correlation coefficients $=0.46-0.77$ over 2 weeks and 0.24-0.67 over 12 weeks), and good discriminant validity (between anxiety and non-anxiety disorders) ${ }^{16}$ Total scores range from 0 to 83 with each statement having a rating from 0 to 2. Higher scores indicate more severe anxiety symptoms. Scoring 25 and higher indicates the presence of an anxiety disorder.

Social support: The Scale of Social Support for Adolescents (SSSA) scale was developed by Ye et $a l^{17}$ and is a Chinese version designed to measure children's resources and utilisation of social support. The scale includes 17 items. Perceived social support from family, friends and relatives is recorded on three subscales: subjective support, objective support and utilisation of social support. The $\alpha$ coefficients of the total and three subscales range from 0.81 to 0.91 .

\section{Procedure}

The survey was conducted between 1 and 31 December 2012. Questionnaires were completed using a group 
administration format in classrooms. Trained research assistants administered the survey. Students were recruited for the project with approval from school officials and their guardians. The aim of the survey was introduced to the students and informed consent was obtained before completing the questionnaire. No names were collected. During the survey administration, students were not allowed to talk to each other. To ensure quality responses and correct understanding of the questions, assistants walked around the classroom to help those who were having difficulty. Students were told that there were no right or wrong answers and that they could withdraw from the study at any time.

\section{Statistical analysis}

Differences in demographics (age, grade, sex, whether or not they were an only child), academic performance at school, eyesight, disabilities, unintentional injury and physical abuse and levels of social support between children stratified by parental migration status (no parent migrating, one parent migrating and both parents migrating) were determined using $\chi^{2}$ test. An unconditional, multivariate logistic regression was performed to calculate the ORs and 95\% CIs to explore the factors that were related to depression and anxiety risk. The dependent variables in this study were age; grade; sex; whether or not he/she is an only child; children with no, one or both parents migrating; sleep difficulty; staying up late; time spent watching TV and using the internet; social support; unintentional injury and physical abuse. All tests were two tailed and significance was determined using $<0.05$. SAS V.9.4 was used for statistical analysis.

\section{RESULTS}

The mean age of students was $14.22 \pm 1.71$ years. Boys and girls accounted for $45 \%$ and $55 \%$, respectively, of the sample. A total of $1397(61.2 \%)$ children were leftbehind children; among those, $1185(84.5 \%)$ had one parent migrating and $212(15.5 \%)$ had both parents migrating. For left-behind children, caregivers were mothers $(1160,83 \%)$, grandparents $(131,9.4 \%)$, fathers $(25,1.8 \%)$ and other relatives $(81,5.8 \%)$.

Table 1 shows the demographic information of leftbehind children and non-left-behind children, and the proportion being left behind was similar between boys and girls. Most parents' education was middle and primary school among left-behind children.

The overall prevalence rates of anxiety and depression were $28.2 \%$ and $12.3 \%$, respectively (table 2). Left-behind children had higher rates of depression than non-left-behind children, but children with no parent migrating had higher rates of anxiety disorder than left-behind children. Children with both parents migrating had a significantly higher prevalence rate of unintentional injury $(12.3 \%)$ than those with no parent migrating $(4.6 \%)$ and one parent migrating $(6.0 \%)$ $(\mathrm{p}<0.05)$. The pattern of physical abuse was similar with no significant differences across groups. There were significant differences among the proportion playing computer games, spending time on the internet and watching TV among children by parental migration status $(\mathrm{p}<0.01)$.

The average social support score was $69.66 \pm 11.33$. According to this, we defined the total score below 58 as low-level social support, 59-80 as middle-level social support, and higher than 81 as high-level social support. Overall, children who had high-level social support had lower rates of physical abuse and mental disorder $(p<0.01)$. Children with low-level social support had higher prevalence rates of anxiety and depression, and were exposed to more unintentional injury and physical abuse. When stratified by parents' migration status, children with both parents migrating and with one parent migrating who had low-level social support had higher rates of anxiety disorder $(34.7 \%$ and $36.5 \%$, respectively) compared with children who had no parents migrating $(32.7 \%)$. Children with both parents migrating and low-level social support had a higher prevalence rate of depression $(34.2 \%)$ than the other two groups of children (table 3 ).

Table 4 shows risk factors for depression and anxiety disorder based on multivariate logistic regression analysis. Parental migration status did not enter the final models of depression and anxiety disorders (table 4). Having difficulty sleeping and low-level social support were significantly associated with depression and anxiety disorders $(\mathrm{p}<0.01)$. Sleep-related problems increased the risk of mental disorders, having difficulty falling asleep, and staying up late elevated the risk of depression $(\mathrm{OR}=2.04,95 \%$ CI 1.48 to 2.82 , and $\mathrm{OR}=1.67,95 \%$ CI 1.17 to 2.39 , respectively). Difficulty falling asleep also increased the likelihood of anxiety disorder $(\mathrm{OR}=1.67,95 \%$ CI 1.33 to 2.10$)$.

Students with poor eyesight and poor academic performance at school had higher rates of depression compared with students with good or excellent academic performance. Being a girl and a high school student was significantly associated with higher anxiety. Unintentional injury and physical abuse increased the risk of anxiety disorder in this study.

\section{DISCUSSION}

In this cross-sectional study, $61.1 \%$ of children were leftbehind children. Among those, left-behind children living with a mother or father accounted for $83 \%$ and $1.8 \%$ of the study population, respectively. The prevalence rates of depression and anxiety disorders among rural students were $12.3 \%$ and $23.2 \%$, respectively. There were no significant differences in prevalence of depression and anxiety disorders among children based on parents' migration status. The prevalence rate of depression was similar to that of previous studies among middle school students in China. ${ }^{18}{ }^{19}$ However, the 
Table 1 Demographic characteristics of 2283 children in rural schools, North China

\begin{tabular}{|c|c|c|c|}
\hline Demographic characteristics & Total & Left-behind children (\%) & $\begin{array}{l}\text { Children with no parents } \\
\text { migrating (\%) }\end{array}$ \\
\hline \multicolumn{4}{|l|}{ Gender } \\
\hline Boys & 1027 & $632(45.2)$ & $395(44.6)$ \\
\hline Girls & 1256 & $765(54.8)$ & $491(55.4)$ \\
\hline \multicolumn{4}{|l|}{ Age group, years* } \\
\hline $10-12$ & 400 & $234(16.8)$ & $166(18.7)$ \\
\hline $13-15$ & 1398 & $885(63.4)$ & $513(57.9)$ \\
\hline $16-18$ & 485 & 278 (19.9) & 207 (23.4) \\
\hline \multicolumn{4}{|l|}{ Grade $^{\star \star}$} \\
\hline Junior (7th-9th) & 1830 & $1182(84.6)$ & $648(73.1)$ \\
\hline Senior (10th-12th) & 453 & $215(15.4)$ & 238 (26.9) \\
\hline \multicolumn{4}{|l|}{ Academic performance at school } \\
\hline Excellent/good & 1093 & 667 (47.7) & $426(48.1)$ \\
\hline Middle & 945 & $592(42.4)$ & $353(39.8)$ \\
\hline Low & 245 & $138(9.9)$ & $107(12.1)$ \\
\hline \multicolumn{4}{|l|}{ Eyesight* } \\
\hline Normal & 1335 & $844(60.4)$ & $491(55.4)$ \\
\hline Poor & 948 & $553(39.6)$ & $395(44.6)$ \\
\hline \multicolumn{4}{|l|}{ Only child } \\
\hline Yes & 164 & $98(7.0)$ & $66(7.4)$ \\
\hline No & 2119 & 1299 (93.0) & $820(92.6)$ \\
\hline \multicolumn{4}{|l|}{ Father's education ${ }^{\star \star}$} \\
\hline Primary school or below & 499 & $354(25.3)$ & 145 (16.4) \\
\hline Junior high school & 1382 & $860(61.6)$ & $522(58.9)$ \\
\hline Senior high school or above & 402 & $183(13.1)$ & $219(24.7)$ \\
\hline \multicolumn{4}{|l|}{ Father's occupation ${ }^{\star *}$} \\
\hline Farmer & 1266 & $700(50.1)$ & $566(63.9)$ \\
\hline Non-farmer & 1017 & 697 (49.9) & $320(36.1)$ \\
\hline \multicolumn{4}{|l|}{ Mother's education** } \\
\hline Primary school or below & 1323 & $862(61.7)$ & $461(52.0)$ \\
\hline Junior high school & 723 & 432 (30.9) & 291 (32.8) \\
\hline Senior high school or above & 237 & $103(7.4)$ & $134(15.1)$ \\
\hline \multicolumn{4}{|l|}{ Mother's occupation ${ }^{\star *}$} \\
\hline Farmer & 1403 & $891(63.8)$ & $512(57.8)$ \\
\hline Non-farmer & 880 & $506(36.2)$ & 374 (42.2) \\
\hline Total & 2283 & $1397(100.0)$ & $886(100.0)$ \\
\hline
\end{tabular}

${ }^{*} p<0.05,{ }^{* *} p<0.01$.

finding of no difference in mental disorders between left-behind children and non-left-behind children differed from other studies, which have reported higher mental disorder among left-behind children than non-left-behind children. ${ }^{5}$ 19-23

Our findings suggested that children with both parents migrating were more likely to smoke/drink, which was consistent with previous research. ${ }^{21}$ However, children with no parent migrating were more likely to stay up late, play computer games and have high internet use compared with left-behind children. Children with both parents migrating tended to have more conflict with classmates, higher incidence of fighting and argument with peers, were exposed to unintentional injury and physical abuse, and developed depression, which might be related to poor interpersonal and communication skills for children with both parents away. ${ }^{5}$ Liu et al reported that left-behind children had a higher negative social adjustment than non-left-behind children. ${ }^{24}{ }^{25}$ Even though our findings did not show that mental disorders were related to parent migration statuses, we cannot further conclude that parent migration had no other adverse impacts on their children.

Children with one parent migrating had a similar prevalence rate of mental disorders compared with children living with both parents. Most children with one parent migrating lived with mothers in this study. All children live in school during the week and go back home on weekends, which may result in parental absence having less impact on their daily life. When they come home, caregivers provide them food, clothes and other support. Left-behind children usually had better living conditions than children with no parent migrating. With access to cheap and readily available communication, especially cellular telephones, communication is more frequent and more instantaneous, a development 
Table 2 Proportions of health-related behaviours and mental disorders by parenting migration status in North China $(\mathrm{N}=2283)$

\begin{tabular}{|c|c|c|c|c|}
\hline $\begin{array}{l}\text { Behaviours and mental } \\
\text { disorders }\end{array}$ & $\begin{array}{l}\text { No parents migrating } \\
(\mathrm{n}=886)\end{array}$ & $\begin{array}{l}\text { One parent migrating } \\
(\mathrm{n}=1185)\end{array}$ & $\begin{array}{l}\text { Both parents migrating } \\
(n=212)\end{array}$ & $\begin{array}{l}\text { Total } \\
(\mathrm{n}=2283)\end{array}$ \\
\hline Smoking/drinking & $36(4.1)$ & $47(4.0)$ & $14(6.6)$ & $97(4.2)$ \\
\hline Staying up late & $157(17.7)$ & $173(14.6)$ & $29(13.7)$ & $359(15.7)$ \\
\hline $\begin{array}{l}\text { Having difficulty falling } \\
\text { asleep }\end{array}$ & $430(48.5)$ & $604(51.0)$ & $111(52.4)$ & $1145(50.2)$ \\
\hline Playing computer game** & $117(13.2)$ & $88(7.4)$ & $24(11.3)$ & $229(10.0)$ \\
\hline Conflicts with classmates & 339 (38.3) & $452(38.1)$ & $87(41.0)$ & $878(38.5)$ \\
\hline \multicolumn{5}{|l|}{ Time of internet use $(h)^{\star *}$} \\
\hline Never & $300(33.9)$ & $571(48.2)$ & 99 (46.7) & $970(42.5)$ \\
\hline$<2$ & 324 (36.6) & $392(33.1)$ & 74 (34.9) & $790(34.6)$ \\
\hline$\geq 2$ & $262(29.6)$ & $222(18.7)$ & 39 (18.4) & $523(22.9)$ \\
\hline \multicolumn{5}{|l|}{ Time of watching TV $(h)^{\star *}$} \\
\hline$<2$ & $581(65.6)$ & $690(58.2)$ & $123(58.0)$ & $1394(61.1)$ \\
\hline$\geq 2$ & 305 (34.4) & $495(41.8)$ & 89 (42.0) & $889(38.9)$ \\
\hline Unintentional injury* & $41(4.6)$ & $71(6.0)$ & $26(12.3)$ & $138(6.0)$ \\
\hline Physical abuse & $79(8.9)$ & $110(9.3)$ & $26(12.3)$ & $215(9.4)$ \\
\hline Anxiety disorder & $222(25.1)$ & $261(22.0)$ & 47 (22.2) & $530(23.2)$ \\
\hline Depression & $112(12.6)$ & 139 (11.7) & 30 (14.2) & 281 (12.3) \\
\hline
\end{tabular}

that opens up new possibilities for maintaining family ties despite separation by migration. Therefore, although migrant parents may be physically absent, they may continue parenting from afar.

The long-term impacts of traditional concepts lead parents to focus almost exclusively on their children's academic performance rather than on psychological well-being. ${ }^{26}$ When children do not study hard, beating and scolding are common punishments used by parents. The results indicated that physical punishment increased the risk of anxiety disorder ( $\mathrm{OR}=1.5,95 \%$ CI 1.04 to 2.15), especially for children living with both parents and with mothers. However when both parents migrated to the city, grandparents took the role of caring for leftbehind children. Grandparents often spoil the children and will not punish them if they fail examinations, but

Table 3 Social support and trauma exposure, mental health stratified by parents' migrating status among rural children in North China $(\mathrm{N}=2283)$

\begin{tabular}{|c|c|c|c|c|c|}
\hline \multirow[b]{2}{*}{ Injury or mental disorder } & \multicolumn{3}{|c|}{ Social support } & \multirow[b]{2}{*}{$\chi^{2}$} & \multirow[b]{2}{*}{ p Value } \\
\hline & Low level & Middle level & High level & & \\
\hline \multicolumn{6}{|l|}{ Total } \\
\hline Anxiety & $132(34.7)$ & $341(22.7)$ & $57(14.1)$ & 47.10 & $<0.0001$ \\
\hline Depression & $110(29.0)$ & $148(9.9)$ & $23(5.7)$ & 122.03 & $<0.0001$ \\
\hline Unintentional injury & $33(8.7)$ & $80(5.3)$ & $25(6.2)$ & 6.02 & 0.0494 \\
\hline Physical abuse & $61(16.1)$ & 139 (9.3) & $15(3.7)$ & 34.98 & $<0.0001$ \\
\hline \multicolumn{6}{|l|}{ No parents migrating } \\
\hline Anxiety & 49 (32.7) & $143(24.9)$ & $30(18.6)$ & 8.17 & 0.0168 \\
\hline Depression & $41(27.3)$ & $60(10.4)$ & $11(6.8)$ & 36.77 & $<0.0001$ \\
\hline Unintentional injury & $14(9.3)$ & $17(3.0)$ & $10(6.2)$ & 12.08 & 0.0024 \\
\hline Physical abuse & $25(16.7)$ & $46(8.0)$ & $8(5.0)$ & 14.78 & 0.0006 \\
\hline \multicolumn{6}{|l|}{ One parent migrating } \\
\hline Anxiety & 69 (36.5) & $170(21.46)$ & $22(10.8)$ & 38.23 & $<0.0001$ \\
\hline Depression & 55 (29.1) & $74(9.3)$ & $10(4.9)$ & 68.62 & $<0.0001$ \\
\hline Unintentional injury & $14(7.4)$ & $46(5.8)$ & $11(5.4)$ & 0.85 & 0.6537 \\
\hline Physical abuse & $31(16.4)$ & $75(9.5)$ & $4(2.0)$ & 24.40 & $<0.0001$ \\
\hline \multicolumn{6}{|l|}{ Both parents migrating } \\
\hline Anxiety & $14(34.2)$ & $28(21.1)$ & $5(13.2)$ & 5.29 & 0.0709 \\
\hline Depression & $14(34.2)$ & $14(10.5)$ & $2(5.3)$ & 17.40 & 0.0002 \\
\hline Unintentional injury & 5 (12.2) & $17(12.8)$ & $4(10.5)$ & 0.14 & 0.9324 \\
\hline Physical abuse & $5(12.2)$ & $18(13.5)$ & $3(7.9)$ & 0.87 & 0.6461 \\
\hline
\end{tabular}


Table 4 OR and $95 \%$ Cls of depression and anxiety disorder by multivariable logistic regression model among rural children, North China $(\mathrm{N}=2283)$

\begin{tabular}{|c|c|c|c|c|}
\hline \multirow[b]{2}{*}{ Variables } & \multicolumn{2}{|c|}{ Depression } & \multicolumn{2}{|c|}{ Anxiety disorder } \\
\hline & $\overline{\text { OR }}$ & $95 \% \mathrm{Cl}$ & $\overline{\text { OR }}$ & $95 \% \mathrm{Cl}$ \\
\hline Gender (girl:boy) & & & 2.09 & $(1.64 \text { to } 2.66)^{\star \star}$ \\
\hline Grade (senior high school:junior high school) & & & 1.80 & $(1.38 \text { to } 2.36)^{\star \star}$ \\
\hline Only child (yes:no) & 1.73 & $(1.04 \text { to } 2.89)^{\star}$ & & \\
\hline Having difficulty falling asleep (yes:no) & 2.04 & $(1.48 \text { to } 2.82)^{\star \star}$ & 1.67 & $(1.33 \text { to } 2.10)^{\star \star}$ \\
\hline Staying up late (yes:no) & 1.67 & $(1.17 \text { to } 2.39)^{\star *}$ & & \\
\hline Eyesight (poor:good) & 1.51 & $(1.12 \text { to } 2.03)^{\star \star}$ & & \\
\hline Anxiety disorder (yes:no) & 4.18 & $(3.08 \text { to } 5.67)^{\star *}$ & & \\
\hline Depression (yes:no) & & & 4.09 & $(3.02 \text { to } 5.55)^{\star \star}$ \\
\hline Physical abuse (yes:no) & & & 1.50 & $(1.04 \text { to } 2.15)^{*}$ \\
\hline \multicolumn{5}{|l|}{ Social support } \\
\hline High level $(\geq 81)$ & 1.00 & & 1.00 & \\
\hline Middle level (59-80) & 1.28 & (0.76 to 2.14$)$ & 1.82 & $(1.30 \text { to } 2.56)^{\star \star}$ \\
\hline Low level $(\leq 59)$ & 3.46 & $(2.00 \text { to } 6.01)^{\star *}$ & 2.17 & $(1.44 \text { to } 3.28)^{\star \star}$ \\
\hline \multicolumn{5}{|l|}{ Academic performance at school } \\
\hline Excellent/good & 1.00 & & & \\
\hline Middle & 2.37 & $(1.70 \text { to } 3.30)^{*}$ & & \\
\hline Low & 3.01 & $(1.92 \text { to } 4.72)^{*}$ & & \\
\hline \multicolumn{5}{|l|}{ Time of internet use (h) } \\
\hline Never & 1.00 & & 1.00 & \\
\hline$<2$ & 0.66 & $(0.46 \text { to } 0.94)^{*}$ & 1.43 & $(1.10 \text { to } 1.85)^{\star \star}$ \\
\hline$\geq 2$ & 0.70 & (0.48 to 1.03$)$ & 1.44 & $(1.17 \text { to } 2.39)^{*}$ \\
\hline
\end{tabular}

may ignore the mental health of their grandchildren. ${ }^{22}{ }^{27-29}$ In this study, there was no significant difference in the prevalence rates of physical abuse by parent migration statuses $(p>0.05)$. Children with both parents migrating had higher rates of unintentional injury than did children with no parent migrating, which was consistent with previous studies in China. ${ }^{30-32}$ Research demonstrated that left-behind children spent more time on farm work and domestic work ${ }^{33}$ and had higher exposure to agricultural hazards and higher farm-related injures than non-left-behind children. ${ }^{34}$ Those early adversities may contribute to elevated initial depressive symptom levels through the increase in adaptive challenges for children already dealing with the stressful demands and circumstances that occur during this period.

Labour migration is a common event in developing countries, and studies have shown that left-behind children expressed greater feelings of anger, confusion and worry when compared with their peers. ${ }^{9} 35{ }^{36}$ Chinese left-behind children experienced significant mental health problems (eg, psychosocial dysfunction, and emotional and behavioural problems) in different parts of China. ${ }^{37}$ Studies found that children with both parents migrating had the lowest life satisfaction among the three groups of rural children. ${ }^{5}$ However parents' migration status was not associated with depression and anxiety in multivariable regression models in this study, which was consistent with a previous study conducted in Thailand. ${ }^{35}$ A possible explanation may be that most left-behind children lived with mothers. Mothers could provide a link to the relationships with migrating fathers and ensure more frequent communication between children and their fathers. In traditional families, mothers are primary caregivers for children. ${ }^{9}$ In a family, if a mother stays at home when a father leaves, this might mitigate the disadvantage of both parents migrating. The risk factors related to depression and anxiety were similar for the three groups of children, such as interpersonal communication and social support. Low-level social support was significantly associated with depression and anxiety disorders in this study, and had also been found in other studies. ${ }^{70}$ Left-behind children $^{20}$ living with mother/father who had higher social support than those living with other guardians. ${ }^{38}$ From this perspective, at least one parent, especially the mother, should stay with their children because they play an important role for children in coping with adverse events, developing social skills and safety knowledge. Mothers are also important for childhood development in cognition and socialisation.

In this study, we also found that girls and senior high school students had a higher risk of anxiety than boys and junior high school students, but not for depression. Senior high school students faced with college entrance examination, which may lead to psychological stress. Anxiety disorder frequently occurs together with depression and may precede depression in some situations. ${ }^{39}$ This study showed that depression and anxiety disorder increased the risk for each other. Preventions that 
ameliorate depression may also reduce the risk of anxiety. The observation that internet use increased the risk of anxiety but decreased the risk of depression needs further research.

A few limitations of this study should be noted. First, despite the efforts to ensure the representativeness of the sample, the participants were a convenience sample from one rural county in North China, thereby limiting our ability to generalise the findings to left-behind children in other areas of the country. Second, a crosssectional design prevents a trajectory analysis of mental disorder and a causal interpretation of the findings. For example, sleep problems might be a cause or a consequence of depression and anxiety. Further study is needed to explore these issues using longitudinal study design. Third, the sample was recruited from schools, which limited our ability to examine the impact of parental migration on school attendance. Finally, owing to a small sample of mother-only-migration (only 25 children), we could not assess differences in depression and anxiety disorder comparing mother-only-migration and father-only-migration.

\section{CONCLUSIONS}

Despite these potential limitations, this study makes a significant contribution to existing research by elucidating psychological development of children with parents' migration. Future health promotion and intervention efforts should seek to increase the public attention to the mental healthcare of left-behind children and take measures to promote their social communication skills and social support, especially for children with both parents migrating.

Acknowledgements The authors thank the Hong Kong Yuen Yuen Institute and Dr Weiqi Tang who made donations towards 'The Joint School Education, Social Science and Medical Research Paper Award Scheme', and thank Professor Zuyi Du who is one of the pioneers of the projects. They also thank the schools for providing administration for this survey.

Contributors MS conceived and designed the project; planned the statistical analysis; as well as wrote and revised the manuscript. JG and ZL collected, managed and analysed the data, and provided comments on the draft manuscript. YW and YD contributed to data interpretation for important intellectual content. LS provided a critical review and thoroughly edited the manuscript and also checked the English language grammar.

Funding The Hong Kong Joint School Education, Social Science and Medical Research Paper Award Scheme, No: YX12002.

\section{Competing interests None declared.}

Ethics approval This study was approved by the Ethics Committee of Tongji Medical College, Huazhong University of Science and Technology, Wuhan, China.

Provenance and peer review Not commissioned; externally peer reviewed.

Data sharing statement No additional data are available.

Open Access This is an Open Access article distributed in accordance with the Creative Commons Attribution Non Commercial (CC BY-NC 4.0) license, which permits others to distribute, remix, adapt, build upon this work noncommercially, and license their derivative works on different terms, provided the original work is properly cited and the use is non-commercial. See: http:// creativecommons.org/licenses/by-nc/4.0/

\section{REFERENCES}

1. China Women's Federation. The study of left-behind children and migrating children in China, 2013. Secondary: The study of left-behind children and migrating children in China. 2013. http:// www.ce.cn/xwzx/gnsz/gdxw/201305/10/t20130510_24368366.shtml (accessed 5 Oct 2013).

2. Fan X, Liu Q, Liu Y. A social adaptation comparison of migrant children, rear children, and ordinary children. J Beijing Normal Univ (Soc Sci) 2009;215:33-40.

3. Fan F, Su L, Gill MK, et al. Emotional and behavioral problems of Chinese left-behind children: a preliminary study. Soc Psychiatry Psychiatr Epidemiol 2010;45:655-64.

4. Li X, Yuan J, Gao W, et al. Research on negative emotions, behavior, personal relationship caused by left-behind experience of rural children after growing up. China J Health Psychol 2010;18:92-4.

5. Su S, Li X, Lin D, et al. Psychological adjustment among left-behind children in rural China: the role of parental migration and parent-child communication. Child Care Health Dev 2013;39:162-70.

6. Liu Z, Li X, Ge X. Left too early: the effects of age at separation from parents on Chinese rural children's symptoms of anxiety and depression. Am J Public Health 2009;99:2049-54.

7. Wang YJ, He BY, Fang LH, et al. [Preliminary study on the health status among the "left-behind" children in the Xiantao rural area of Hubei Province]. Zhongguo Dang Dai Er Ke Za Zhi 2011;13:977-80.

8. Valtolina GG, Colombo C. Psychological well-being, family relations, and developmental issues of children left behind. Psychol Rep 2012;111:905-28

9. Asis M. Living with migration: experiences of children left-behind in Philippines. Asia Popul Stud 2006;2:45-67.

10. Macours K, Vakis R. Seasonal migration and early childhood development. World Dev 2010;38:857-69.

11. Morooka $\mathrm{H}$, Liang Z. International migration and education of left behind children in Fujian, China. Asian Pac Migr J 2009;18:345-70.

12. Kovacs M, ed. Manual of the Children's Depression Inventory. Toronto: Multi-Health Systems, 1992.

13. Yu D, Li X. Preliminary use of the Children's Depression Inventory in China. Chinese Mental Health J 2000;14:225-7.

14. Wu WF, Lu YB, Tan FR, et al. Reliability and validity of the Chinese version of Children's Depression Inventory. Chin Ment Health J 2010;24:775-9.

15. Birmaher B, Khetarpal S, Brent D, et al. The Screen for Child Anxiety Related Emotional Disorders (SCARED): scale construction and psychometric characteristics. J Am Acad Child Adolesc Psychiatry 1997;36:545-53.

16. Su L, Wang K, Fan F, et al. Reliability and validity of the Screen for Child Anxiety Related Emotional Disorders (SCARED) in Chinese children. J Anxiety Disord 2008;22:612-21.

17. Ye YM, Dai XY. Development of social support scale for university students. Chin J Clin Psychol 2008;16:456-8.

18. $\mathrm{Xu} \mathrm{J}$, Lin DN, Wang JJ, et al. Comparison of influential factors for depressive symptoms among primary school students in Hefei and Shenzhen. Chin Ment Health J 2008;22:246-9.

19. Zhou Z, Wang J. Depression and related factors analysis among rural students in primary and middle schools. Acta Univ Med Anhui 2011;46:976-8.

20. He B, Fan J, Liu N, et al. Depression risk of 'left-behind children' in rural China. Psychiatry Res 2012;200:306-12.

21. Gao Y, Li LP, Kim JH, et al. The impact of parental migration on health status and health behaviours among left behind adolescent school children in China. BMC Public Health 2010;10:56.

22. Gao WB, Wang T, Liu ZK, et al. A study on depression characteristics and its influencing factors in children left in rural areas [in Chinese]. Chin J Behav Med Sci 2007;16:238-40.

23. Zhou L, Gao YF, Qiu HT, et al. Mental health, life events and coping styles of middle school students left by parents in Rural area. Chin Ment Health J 2008;22:796-800.

24. Lin $\mathrm{XH}$, Shen M, Wang L, et al. Meta-analysis on the mental health of the left-in-hometown children in rural China. Acta Med Univ Sci Technol Huazhong 2010;39:228-31.

25. Liu X, Zhang YB, Song AQ, et al. Meta-analysis on mental health of left-behind children. Chin J Child Health Care 2013;21:68-70.

26. Aldinger C, Zhang XW, Liu LQ, et al. Changes in attitudes, knowledge and behavior associated with implementing a comprehensive school health program in a province of China. Health Educ Res 2008;23:1049-67.

27. Zhou FL, Duan CR. Literature review on studies on left behind children [in Chinese]. Popul Res 2006;3:60-5.

28. Huang XN, Wu J, Peng AN, et al. Left behind children, a group of vulnerable population [in Chinese]. Med Soc 2005; 18:5-6. 
29. Wang LF, Zhang S, Sun YH, et al. The current situation of loneliness of left behind children in countryside [in Chinese]. Chin J Behav Med Sci 2006(15):639-40.

30. Shen M, Yang S, Han J, et al. Non-fatal injury rates among the "left-behind children" of rural China. Inj Prev 2009;15:244-7.

31. Jiang W, Huang HX, Wei JL, et al. Epidemiology investigation on unintentional injuries in left-behind children in rural area of Nanning [in Chinese]. Matern Child Health Care China 2010;26:563-5.

32. Zhao KF, Su H, Fang XH, et al. [Study on the distribution and risk factors of injuries among home-stranded children in rural area of Anhui province]. Zhonghua Liu Xing Bing Xue Za Zhi 2008;29:338-42.

33. CHang HQ, Dong $X Y$. Labor migration and time use patterns of the left-behind children and elderly in rural china. World Dev 2011;39:2199-210.

34. Shen M, Wang Y, Yang S, et al. Agricultural exposures and farm-related injuries among adolescents in rural China. Inj Prev 2013;19:214-17.
35. Adhikari R, Jampaklay A, Chamratrithirong A, et al. The impact of parental migration on the mental health of children left behind. J Immigr Minor Health 2014;16:781-9.

36. Senaratne BC, Perera H, Fonseka P. Mental health status and risk factors for mental health problems in left-behind children of women migrant workers in Sri Lanka. Ceylon Med J 2011;56: 153-8.

37. Jia Z, Shi L, Cao Y, et al. Health-related quality of life of "left-behind children": a cross-sectional survey in rural China. Qual Life Res 2010;19:775-80.

38. Hu K. Research on the status of social supports of the rural left-behind children. China J Health Psychol 2011; 19:976-8.

39. Woo B. Emotional disorders. In: Fung D, Yiming C, eds. A primer of child and adolescent psychiatry. Singapore: World Scientific Publishing Co, Pte. Ltd., 2008:59. 